\title{
Gestão ambiental de rodovias: avaliação do potencial ecotoxicológico do material fresado de pavimentos asfálticos
}

\section{André Nagalli*, Lucia Regina Rocha Martins, Thomaz Aurélio Pagioro, Mariana Reinert Schroh e Diego Moraes}

Universidade Tecnológica Federal do Paraná - UTFPR. Rua Deputado Heitor de Alencar Furtado, 5.000. Curitiba-PR, Brasil (CEP 81280-340). *E-mail: nagalli@utfpr.edu.br.

Resumo. Os padrões atuais de gestão ambiental de rodovias impõem o compromisso do adequado destino e utilização dos materiais de construção e resíduos. Os materiais de fresagem de pavimentos asfálticos vem sendo incorporados na confecção de novos pavimentos. Ocorre que o material fresado muitas vezes é estocado sob a forma de pilhas diretamente sobre o solo visando à utilização futura ou ainda simplesmente aterrados. 0 presente estudo buscou verificar o potencial efeito ecotoxicológico de águas que entram em contato com este tipo de material. Foram testados cinco tipos de amostras, em ensaios de lixiviação por diferentes métodos, cujos líquidos foram postos em contato com o microcrustáceo Daphnia magna, a fim de avaliar a toxicidade aquática aguda, verificando-se sua imobilidade. As amostras foram caracterizadas quanto à sua distribuição granulométrica, massa unitária e teor de betume. Coletaram-se amostras em intervalos de tempo de 30, 60, 90 e 120 min de lixiviação, em regime de recirculação, a uma vazão de $30 \mathrm{~L} / \mathrm{h}$. Verificou-se que o método proposto pela ABNT NBR 10005:2004 foi mais eficiente na mobilização de poluentes das amostras, quando comparado ao aparato experimental de percolação em coluna. Conclui-se que os lixiviados originados a partir das amostras analisadas apresentam ecotoxicidade, com fatores de diluição que variaram de 16 a 32 vezes em amostras analisadas pelo método da ABNT NBR 10005:2004. Observou-se que mesmo amostras submetidas a longos períodos de intemperismo possuem característica ecotoxicidade, de modo que cuidados técnicos na estocagem e aterramento deste tipo de material são recomendados.

Palavras-chave: RAP; Resíduos asfálticos; Concreto betuminoso; Concreto asfáltico; CBUQ.

Abstract. Environmental management of highways: Evaluation of the ecotoxicological potential of the milled material of asphalt pavements. Current standards of environmental management of highways impose the commitment of the appropriate destination and use of construction materials
Recebido

05/12/2019

Aceito

$12 / 04 / 2020$

Disponível on line

$13 / 04 / 2020$

Publicado

$30 / 04 / 2020$

Acesso aberto

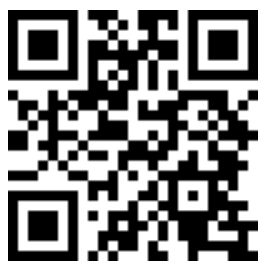

ORCID

(D) 0000-0002-3985-755X André Nagalli

D) 0000-0002-9018-7176

Lucia Regina Rocha

Martins

D) $0000-0002-2169-6989$

Thomaz Aurélio

Pagioro

D 0000-0002-8298-0553

Mariana Reinert

Schroh

ISSN 2359-1412/RBGAS-2019-0102/2020/7/15/7/83

Rev. Bras. Gest. Amb. Sustent.

http://revista.ecogestaobrasil.net 
and waste. Reclaimed Asphalt Pavement have been incorporated into the making of new floors. It occurs that the milled material is often stocked in the form of batteries directly on the ground for future use or even simply grounded. The present study sought to verify the potential ecotoxicological effect of waters that come into contact with this type of material. Five types of samples were tested in leaching tests by different methods, whose liquids were put in contact with the microcrustacean Daphnia magna, in order to evaluate acute aquatic toxicity, verifying their immobility. The samples were characterized for their granulometric distribution, unit mass and bitumen content. Samples were collected at time intervals of $30,60,90$ and $120 \mathrm{~min}$ of leaching, under recirculation, at a flow rate of $30 \mathrm{~L} / \mathrm{h}$. It was found that the method proposed by ABNT NBR 10005:2004 was more efficient in mobilizing pollutants from the samples when compared to the experimental column percolation apparatus. It was concluded that leached originating from the analyzed samples present ecotoxicity, with dilution factors ranging from 16 to 32 times in samples analyzed by the ABNT NBR 10005:2004 method. It was observed that even samples submitted to long periods of weathering have an ecotoxicity characteristic, so that technical care in storage and grounding of this type of material is recommended.

Keywords: RAP; Asphalt residues; Bituminous concrete; Asphalt concrete; CBUQ District.
D $0000-0002-3992-3131$

Diego Moraes

\section{Introdução}

No Brasil, o transporte rodoviário tem relevante importância econômica. É através deste que as diversas regiões estão interligadas e é este quem possibilita o escoamento das produções agrícolas, agropecuárias e industriais de diversas áreas até seus mercados consumidores. Possibilita, também, a ligação da produção interna com os meios multimodais, viabilizando a exportação. 0 investimento nesse tipo de transporte fomenta a estruturação das cidades e impulsiona o desenvolvimento econômico do país.

Em 2017, o Produto Interno Bruto (PIB) brasileiro cresceu 1,0\%, influenciado principalmente pelo crescimento de $13 \%$ no setor agropecuário, fato que, aliado à estabilidade da atividade do transporte neste ano e à safra recorde nos anos de 2016-2017, culminou em avanço de 0,9\% no setor de transporte (CNT, 2018).

Além disso, é o meio de transporte de passageiros utilizado com maior frequência pela população, por ser mais viável financeiramente, principalmente quando comparado com transporte aéreo de passageiros. Segundo a Confederação Nacional do Transporte, essa modalidade corresponde a $96,2 \%$ da matriz de transporte de passageiros e $61,8 \%$ do transporte de cargas. Em 2016, foram mais de 83 milhões de passageiros transportados através da malha rodoviária regular (CNT, 2018).

Considerando apenas a pavimentação rodoviária, de acordo com dados presentes no último anuário CNT do Transporte (CNT, 2018), dos 1,7 milhões de km de rodovias implantadas no país, apenas $12,2 \%$ são pavimentadas. Considerando apenas o item pavimento, das rodovias avaliadas no Brasil em 2016, apenas 51,7\% estão classificados como "ótimo" ou "bom", 35,8\% como "regular" e 12,5\% como "ruim" ou "péssimo". 
Estes dados pressupõem a demanda por obras de pavimentação nas rodovias não pavimentadas, bem como obras de manutenção das rodovias já pavimentadas. 0 método usual para correção de danos na pavimentação é por corte e trituração para remoção da camada deteriorada, em espessura pré-determinada, realizada por equipamento específico, dotado de cilindro com dentes de corte. Este método é denominado fresagem e é corriqueiro no Brasil para evitar problemas funcionais e de segurança da pista (Bonfim, 2011). 0 material proveniente da fresagem é conhecido como RAP (Reclaimed Asphalt Pavement) ou material fresado.

É possível reciclar esse resíduo, utilizando-o para compor a nova camada da pavimentação, com o acréscimo de cimento asfáltico de petróleo (CAP) ou de emulsão asfáltica de petróleo (EAP) (Fonseca, 2002). Dessa maneira, há reabilitação do pavimento sem alterar sua altura, para obter características semelhantes ou superiores ao pavimento antigo, ao mesmo tempo em que se preservam recursos minerais escassos.

Porém, quando o material fresado não é reaproveitado em sua totalidade este usualmente é disposto diretamente sobre o solo, sob a forma de aterro. $\mathrm{Ou}$ ainda, quando $\mathrm{o}$ reaproveitamento do material não é imediato, costuma ser estocado provisoriamente em pilhas, também diretamente sobre o solo.

Em meados da década de 1990, Sadecki et al. (1996), estudaram a qualidade da água lixiviada em amostras de pavimento betuminoso, analisando a presença de hidrocarbonetos policíclicos aromáticos (HPAs). Neste estudo, as concentrações de HPAs ficaram levemente acima ou abaixo do limite de detecção do cromatógrafo utilizado à época, porém já indicava preocupação dos autores neste sentido. Nos anos seguintes diversos autores (Legret et al., 2005; Zhang et al., 2015; Yusuf et al., 2017) confirmaram a presença de poluentes no RAP, ampliando a discussão.

Com a finalidade de atestar o uso de RAP para preenchimento de aterros, Brantley and Townsend (1999) utilizaram os procedimentos descritos em SW-846 Test Method 1311: Toxicity Characteristic Leaching Procedure da United States Environmental Protection Agency (USEPA), o qual descreve método de lixiviação para caracterizar a periculosidade de resíduos através da toxicidade. Esse método foi referência para a norma ABNT NBR 10.005 (ABNT, 2004b). Os lixiviados foram analisados para metais pesados através de espectrofotometria de absorção atômica por chama (flame atomic absorption spectrophotometer - FAAS) e para HPAs e compostos orgânicos voláteis por cromatógrafo gasoso com espectrometria de massa acoplado. Com exceção do HPA naftaleno, os níveis ficaram abaixo do limite de detecção.

Para o estudo citado, partiram-se da premissa da presença de HPAs e de metais pesados em fresados asfálticos e, por consequência, a possibilidade da presença desses compostos nos lixiviados desse tipo de material. A presença desses compostos seria originada da própria composição química do asfalto bem como resultado do tráfego de veículos sobre o pavimento asfáltico.

Mais recentemente, Butera et al. (2014) observaram que, dentre os resíduos de construção civil obtidos de aterro dinamarquês, os teores de HPAs quantificados por cromatógrafo gasoso estavam acima do limite permitido em todas as amostras avaliadas que continham resíduo asfáltico.

Segundo Dal Molin et al. (2010), vários são os autores que têm apontado para a necessidade da inclusão do monitoramento biológico para uma real avaliação da qualidade ambiental. As possíveis interações entre substâncias (responsáveis por efeitos sinérgicos) bem como a presença de contaminantes, passíveis de causar danos aos seres vivos, devem ser investigadas utilizando-se ensaios ecotoxicológicos ou toxicológicos, segundo a Resolução CONAMA no 357/2005 (Brasil, 2005).

Embora, normalmente, seja de senso comum que o RAP não cause riscos para a saúde ou meio ambiente, é importante a melhor caracterização deste material para se ampliar os conhecimentos desse tema, ajudando a embasar a decisão do Estado e de 
engenheiros a respeito do melhor gerenciamento e critérios de disposição em solo desse tipo de resíduo. Especialmente, porque pode vir a se tornar uma fonte potencial de poluição difusa.

0 presente estudo objetiva avaliar os efeitos ecotoxicológicos de lixiviado de material fresado de pavimentação asfáltica. 0 termo lixiviação define o processo de extração de constituintes através do escoamento de um fluido, geralmente água, através de elemento sólido. Subsidiariamente, buscou-se conceber metodologia para lixiviação das amostras de resíduos asfálticos, de maneira que se simulasse a precipitação pluvial sobre o fresado (RAP) depositado sobre encostas rodoviárias, aterros ou outros depósitos para resíduos de construção.

\section{Materiais e métodos}

\section{Amostragem, caracterização das amostras e aparato experimental}

Os procedimentos metodológicos foram conduzidos de modo a prospectar amostras de resíduos asfálticos originados de trabalhos de manutenção tanto de pavimentos rodoviários quanto de pavimentos urbanos. Foram coletadas amostras de resíduos de asfaltos que haviam sido aplicados há pouco tempo, bem como de pavimentações asfálticas mais antigas. Também, foi obtida amostra proveniente de usina asfáltica, antes de aplicação em pavimento. A intenção foi observar possíveis variações entre materiais fresados e virgem.

Considerando as premissas definidas, foram coletadas cinco amostras, assim nomeadas: i) amostra 1 - coletado de pavimento urbano do Município de Pinhais, Estado do Paraná; ii) amostra 2 - material fresado da rodovia BR-277; iii) amostra 3 - material recebido de uma usina de asfalto localizada na cidade de Curitiba; iv) amostra 4 - material fresado da rodovia PR-415, e; v) amostra 5 - material de pavimento urbano fresado de via do Município de Curitiba-PR.

As amostras foram coletadas conforme diretrizes das normas ABNT NBR NM 26:2009 (ABNT, 2009) e ABNT NBR 10.007:2004 (ABNT, 2004c). Cada material se originou de máquina fresadora distinta, gerando tamanhos de partículas díspares. Para que o tamanho do grão não interferisse na comparação entre os resultados ecotoxicológicos das diferentes amostras, os grãos de grandes dimensões foram desagregados manualmente com auxílio de martelo a fim de que as partículas alcançassem tamanhos visualmente similares.

Na sequência, a norma ABNT NBR NM 27:2001 (ABNT, 2001) serviu de diretriz para a execução do quarteamento manual. A quantidade quarteada foi armazenada em sacos de polietileno transparente, que foram identificados, refrigerados e protegidos da luz para que posteriormente fosse realizada determinação da massa unitária, conforme ABNT NBR NM 45:2006 (ABNT, 2006), determinação da composição granulométrica, conforme ABNT NBR NM 248:2003 (ABNT, 2003), determinação do teor de betume, conforme ABNT NBR 16.208:2013 (ABNT, 2013) e ABNT NBR 12.713:2016 dos ensaios ecotoxicológicos (ABNT, 2016).

A determinação da curva granulométrica foi realizada de acordo com as indicações da ABNT NBR 248/2003 (ABNT, 2003), após a desagregação dos grãos de cada amostra, visto que os ensaios foram realizados com as partículas dessa maneira. Para determinação do teor de betume de cada amostra, foram consideradas as prescrições da norma ABNT NBR 16.208:2013 (ABNT, 2013).

Para simulação da precipitação pluvial, foi escolhido como líquido extrator água ultrapura obtida no equipamento Mega Purity Water Purification System, da Thermo Fisher Cientific, e optou-se por utilizar vidrarias de vidro borossilicato e mangueiras de silicone, por serem considerados materiais inertes. 
Para simular o cenário real, considerou-se a premissa de que os contaminantes presentes no lixiviado ficariam retidos no solo suporte sobre o qual o material fresado foi disposto, e que sua concentração iria aumentar conforme a ocorrência das precipitações. Então, o líquido extrator deveria recircular por entre a amostra para que o teor contaminante que estaria retido no solo, estivesse presente no lixiviado, para as análises futuras.

Foram testados dois aparatos experimentais. Para o primeiro, cortou-se o fundo de um "garrafão" no qual costumeiramente é comercializado vinho e quentão, com capacidade de $5 \mathrm{~L}$, para se formar um grande funil, conforme demonstrado na Figura $1 \mathrm{~A}$. Nele foi acomodado 1,5 kg de amostra de RAP e a boca foi parcialmente fechada por gaze, para que a amostra não escoasse. 0 garrafão foi apoiado sobre um béquer com capacidade de $2 \mathrm{~L}$ e a recirculação foi feita com auxílio de bomba peristáltica e mangueiras de silicone. 0 volume de $2 \mathrm{~L}$ de líquido extrator foi lançado sobre a amostra através de um chuveirinho de banheiro residencial, para que, ao passar pelos orifícios, o líquido fosse distribuído uniformemente sobre a amostra. Durante o processo de lixiviação, o sistema foi protegido da luz com papel alumínio.

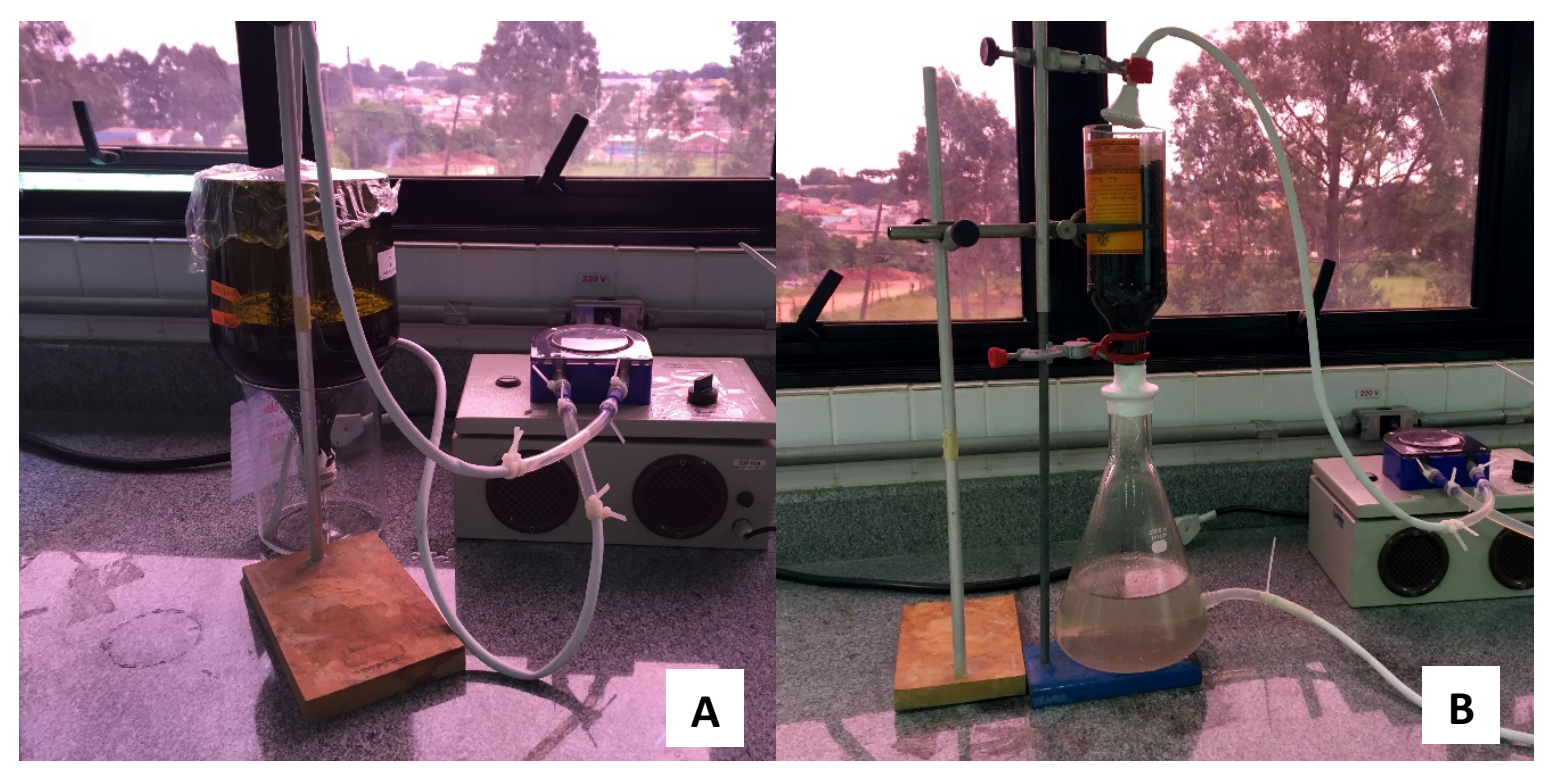

Figura 1. Aparatos experimentais utilizados na geração do lixiviado. A) garrafão; B) garrafa.

Para que toda a superfície da amostra recebesse o líquido extrator por igual (seção uniforme), optou-se por trocar o garrafão de $5 \mathrm{~L}$ por uma garrafa também com o fundo retirado (aparato experimental 2, Figura 1B), com capacidade de $1 \mathrm{~L}$, altura preenchida com amostra de 23,5 cm e diâmetro de $8,5 \mathrm{~cm}$, na qual foi acomodado $1 \mathrm{~kg}$ de amostra. A bomba peristáltica trabalhou em vazão de $30 \mathrm{~L} / \mathrm{h}$. Utilizando este sistema, notou-se que ao longo da realização da lixiviação, as partículas finas da amostra se acumularam no gargalo, criando resistência à passagem da água ultrapura, ocasionando em acúmulo de água sobre a amostra.

Usando como base a vazão previamente escolhida de $30 \mathrm{~L} / \mathrm{h}$, a bomba peristáltica foi substituída por bomba à vácuo, para favorecer a passagem do líquido extrator pela amostra, mesmo com a presença de partículas finas na amostra. Contudo, ainda assim, houve certo acúmulo de água sobre a amostra, fazendo com que o líquido extrator 
ocupasse todo o volume de vazios do material. Diante disso, aceitou-se essa condição e prosseguiram-se com as lixiviações.

Definida a sistemática da lixiviação, foram definidos os outros parâmetros. Primeiramente, foi estabelecido que seriam retiradas alíquotas de lixiviado durante o processo, para avaliar possíveis variações no teor de constituintes desprendidos do resíduo. Então, baseando-se na vazão de trabalho com a bomba peristáltica de $30 \mathrm{~L} / \mathrm{h}$, foi determinado que seriam retiradas alíquotas após 30, 60, 90 e 120 min. de lixiviação.

Contudo, como não é possível precisar a vazão utilizando-se bomba a vácuo, permitiu-se o escoamento de $2 \mathrm{~L}$ de líquido extrator por 7,5 vezes para corresponder à vazão de 30L/h durante 30 minutos. Neste momento, a primeira alíquota foi retirada, identificada, armazenada em vidraria âmbar e refrigerada para ensaios posteriores. Mantendo a porção de amostra na garrafa, mas renovando-se o líquido extrator, o escoamento foi feito por mais 7,5 vezes para corresponder à vazão de $30 \mathrm{~L} / \mathrm{h}$ durante outros $30 \mathrm{~min}$., totalizando $60 \mathrm{~min}$. de lixiviação. 0 processo foi repetido para 90 e 120 min. Por fim, com nova porção da mesma amostra, escoou-se 2 L do líquido lixiviador por 37,5 vezes, correspondendo a 150 minutos de lixiviação consecutivos.

Foi realizada, também, lixiviação seguindo orientações da ABNT NBR 10.005:2004 (ABNT, 2004b) a qual discorre a respeito da obtenção de extrato lixiviado de resíduos sólidos. Essa norma tem como objetivo classificar resíduos como perigosos ou nãoperigosos, de acordo com os parâmetros da ABNT NBR 10.004:2004 (ABNT, 2004a), sendo que a toxicidade do lixiviado caracteriza o resíduo como perigoso.

Para a extração segundo a ABNT NBR 10.005:2004 (ABNT, 2004b), foram utilizadas de cada amostra apenas as partículas passantes por peneira de malha de 9,5 mm. Devido ao pH obtido após extração preliminar em água, a solução de extração utilizada foi a solução no 1 , a qual foi preparada com 5,7 mL de ácido acético glacial PA e 64,3 mL de hidróxido de sódio $1 \mathrm{~N}$ para cada litro de água ultrapura, a qual teve $\mathrm{pH}$ resultante de 4,93 $\pm 0,05$.

0 ensaio foi executado em conformidade com as diretrizes para resíduos com teor de sólidos igual a 100\%, para lixiviação de constituintes não voláteis, tendo em vista a pressuposição da presença de metais e HPAs de maior peso molecular nas amostras dos resíduos. 0 equipamento utilizado foi a incubadora com agitação 530/D da fabricante Nova Ética Produtos e Equipamentos Científicos Ltda, programada para funcionar por 18 horas, em $25{ }^{\circ} \mathrm{C}$ e $30 \mathrm{rpm}$. Em cada ensaio, foram acondicionados 12 erlenmeyers com capacidade para $250 \mathrm{~mL}$, preenchidos com $200 \mathrm{~mL}$ de solução extratora no 1 e $10 \mathrm{~g}$ de amostra. Em seguida, a incubadora foi fechada com tampa própria de acrílico e protegida da luz. Por fim, foi medido o $\mathrm{pH}$ do lixiviado de cada amostra, os quais foram armazenados em vidraria âmbar, identificados e refrigerados.

\section{Método de ensaios para avaliação da ecotoxicidade}

$\mathrm{O}$ ensaio empregado para a avaliação da toxicidade aguda aquática, utilizando o microcrustáceo Daphnia magna, seguiu os procedimentos indicados na norma ABNT NBR 12.713:2016 (ABNT, 2016). Os lotes das culturas-estoque foram cultivados em béqueres com capacidade de $2000 \mathrm{~mL}$, completos de água de cultivo e mantidos em incubadora do tipo BOD, em temperatura de $20^{\circ} \mathrm{C}$ e fotoperíodo de $16 \mathrm{~h}$ de iluminação.

Para garantir a qualidade dos resultados, a sensibilidade dos organismos-testes foi testada quinzenalmente através da substância de referência sulfato de zinco, cujos resultados foram copilados em carta-controle. Para todos os testes, 20 organismos neonatos, entre $2 \mathrm{~h}$ e $26 \mathrm{~h}$ de vida, foram transferidos para cada béquer de vidro com capacidade de $50 \mathrm{~mL}$, preenchidos com $40 \mathrm{~mL}$ de solução, sem fornecimento de alimentação, em triplicada. Também, para cada teste, foi preparado controle com o mesmo número de réplicas e organismos, apenas com água de diluição aerada por, no mínimo, $24 \mathrm{~h}$. 
Os béqueres foram dispostos em bandejas, as quais foram cobertas com papel alumínio, para proteger da luz, e armazenados em incubadora com temperatura entre $18^{\circ} \mathrm{C}$ e $22^{\circ} \mathrm{C}$. Após $48 \mathrm{~h}$ de exposição e sem, os resultados foram expressos em termos de Fator de Toxicidade, a qual indica a menor diluição na qual não se observa imobilidade maior que 10\%. Considerou-se organismo imóvel aquele incapaz de nadar nos $15 \mathrm{~s}$ após agitação ou aquele flutuante na superfície. Em conformidade com a norma, os ensaios foram validados apenas quando o controle apresentou porcentagem de organismos imóveis menor que $10 \%$.

Cada amostra teve alíquotas retiradas da lixiviação as quais representaram tempos de lixiviação e cada alíquota foi diluída até o Fator de Diluição (Fd) igual a 8, representando solução com 12,5\% de lixiviado para 87,5\% de água de diluição.

Devido ao caráter ácido da solução de extração no 1 , utilizada para extração das amostras conforme indicações da ABNT NBR 10.005:2004 (ABNT, 2004b), foi necessário ajustar o pH dos lixiviados previamente a exposição dos organismos-teste. Isso se deu ao fato de soluções com valores de $\mathrm{pH}$ fora da faixa entre 5,0 e 9,0 podem interferir nos resultados dos ensaios (ABNT, 2016). 0 ajuste de $\mathrm{pH}$ foi feito adicionando entre $10 \mathrm{~mL}$ a $20 \mathrm{~mL}$ de $\mathrm{NaOH}$ para cada litro de lixiviado de amostra e para a solução extratora, até que os respectivos valores de $\mathrm{pH}$ estivessem entre 7,6 e 8,0, intervalo indicado para água de diluição (ABNT, 2004b; ABNT, 2016).

Após teste preliminar, a solução extratora no 1 , mesmo com pH ajustado, mostrouse tóxica para os organismos-teste. Portanto, com o objetivo de avaliar a toxicidade dos lixiviados das amostras de resíduo, independente da solução extratora, foi necessário comparar os respectivos fatores de toxicidade (FT). Logo, os organismos foram expostos a gradiente de diluições da solução extratora n⿳0 1, além das diluições dos lixiviados.

\section{Resultados e discussão}

\section{Caracterização das amostras}

A caracterização dos RAP abrangeu a avaliação da distribuição granulométrica das amostras, quantificação da massa unitária e determinação do teor de betume. As amostras analisadas apresentaram perfil granulométrico similar, e uniforme distribuição granulométrica. Desta forma, conclui-se que as áreas de contato entre os grãos e o líquido lixiviante tendem a ser de mesma ordem de grandeza e, consequentemente, o desprendimento de eventuais poluentes deva se dar a taxas similares. Os resultados da medição da massa unitária e do teor de betume das amostras estão apresentados na Tabela 1, em que se observa que a massa unitária da amostra 1 é significativamente menor que a das demais amostras. No que concerne ao teor de betume, nota-se que, como esperado, a amostra 3 é a que apresenta maior percentual, por se tratar de um material "virgem" e, portanto, menos intemperisado.

Tabela 1. Resultados dos ensaios de medição de massa unitária e teor de betume.

\begin{tabular}{|c|c|c|}
\hline Identificação & Massa unitária (kg/m $\mathbf{3})$ & Teor de betume (\%) \\
\hline Amostra 1 & 517,85 & $4,49(0,34)$ \\
\hline Amostra 2 & $1.252,64$ & $5,66(0,50)$ \\
\hline Amostra 3 & $1.121,49$ & $5,74(0,8)$ \\
\hline Amostra 4 & $1.252,32$ & $4,14(0,10)$ \\
\hline Amostra 5 & $1.490,93$ & $4,81(0,07)$ \\
\hline
\end{tabular}




\section{Daphnia magna}

Neste tópico estão demonstrados os percentuais de imobilidade dos organismos quando expostos aos lixiviados das amostras em cada alíquota de lixiviação por coluna de percolação. Também, estão expostos os dados de fator de toxicidade (FT) em cada alíquota de lixiviação. Como é possível verificar nas Figuras 2 e 3, a Amostra 1 se mostrou tóxica aos organismos nas alíquotas $\mathrm{t}=60^{\prime}, \mathrm{t}=90^{\prime}$ e $\mathrm{t}=150^{\prime}$ acumulados. A Amostra 2 não foi tóxica para os organismos-teste, já que o percentual de imobilidade foi menor que 10 quando expostos às alíquotas de lixiviação. A Amostra 3 se mostrou tóxica para os organismos teste em todas as alíquotas avaliadas, sendo que o fator de toxicidade chegou a 4 nas alíquotas de $t=60^{\prime}, t-90^{\prime}$ e $t=150$ ' acumulados. A Amostra 4 não se mostrou tóxica em nenhuma das alíquotas tendo em vista que não houve diferença significativa entre os testes controle e os organismos expostos aos lixiviados. A Amostra 5 se mostrou tóxica para os organismos, com exceção da alíquota $\mathrm{t}=60^{\prime}$.

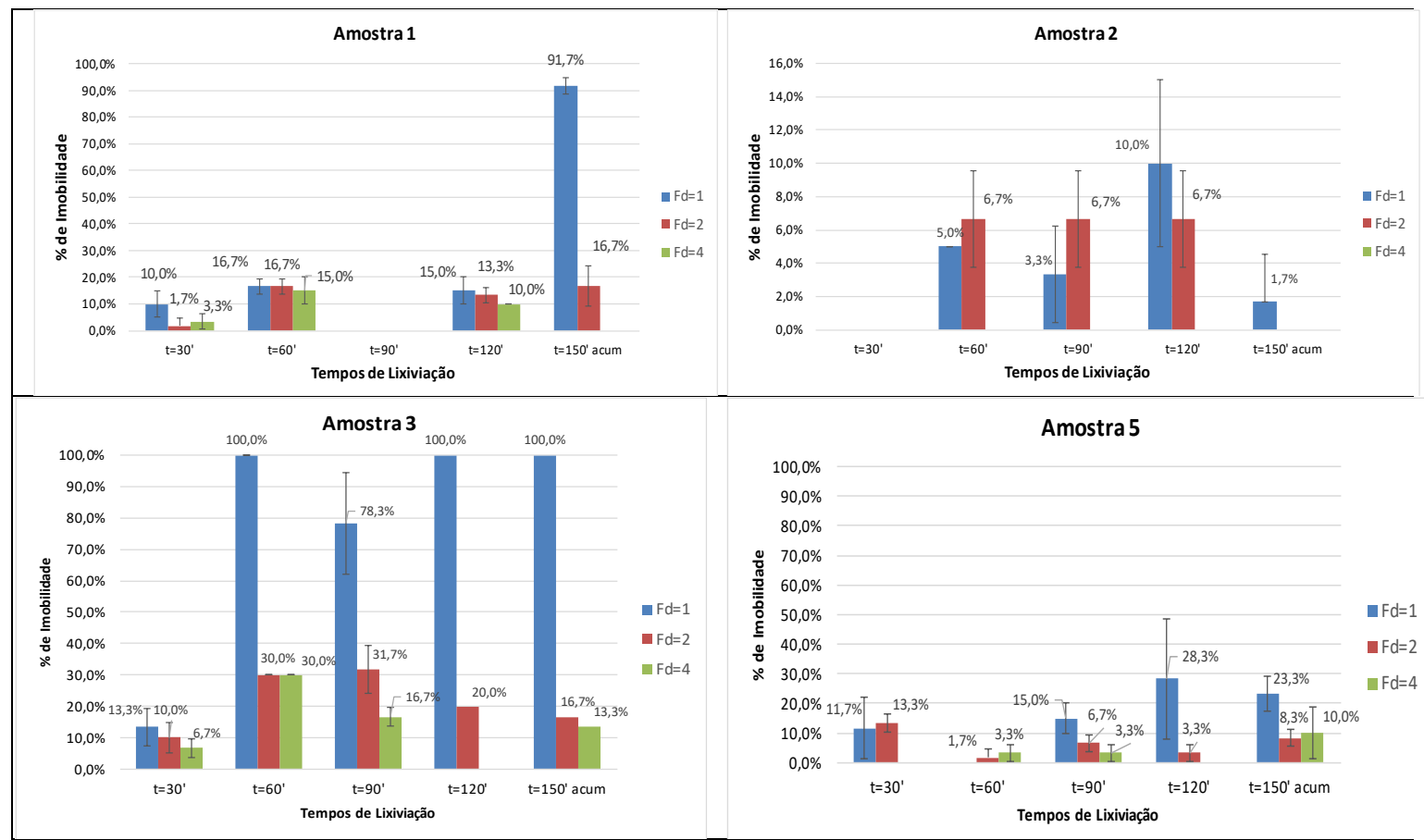

Figura 2. Resultados percentuais de imobilidade em cada tempo de lixiviação.

Considerando a característica ácida da solução extratora utilizada para a lixiviação seguindo as diretrizes da ABNT NBR 10.005 (ABNT, 2004b), foi necessário corrigir o pH dos lixiviados de cada amostra adicionando entre 10 e $20 \mathrm{~mL}$ de hidróxido de sódio $(\mathrm{NaOH}, 1 \mathrm{~N})$ para cada litro de lixiviado previamente à execução dos testes, para que o $\mathrm{pH}$ estivesse na mesma faixa recomendada para a água de diluição, de 7,6 a 8,0.

Entretanto, mesmo após proceder com o ajuste de $\mathrm{pH}$, a solução extratora $\mathrm{n}$ - 1 se mostrou tóxica para os organismos. Então, optou-se por testar também a toxicidade de série de diluições da solução extratora com a finalidade de comparar o fator de toxicidade desta com os lixiviados da amostra. Nesse sentido, foi possível avaliar o incremento no fator de toxicidade dos lixiviados das amostras com relação à solução. 


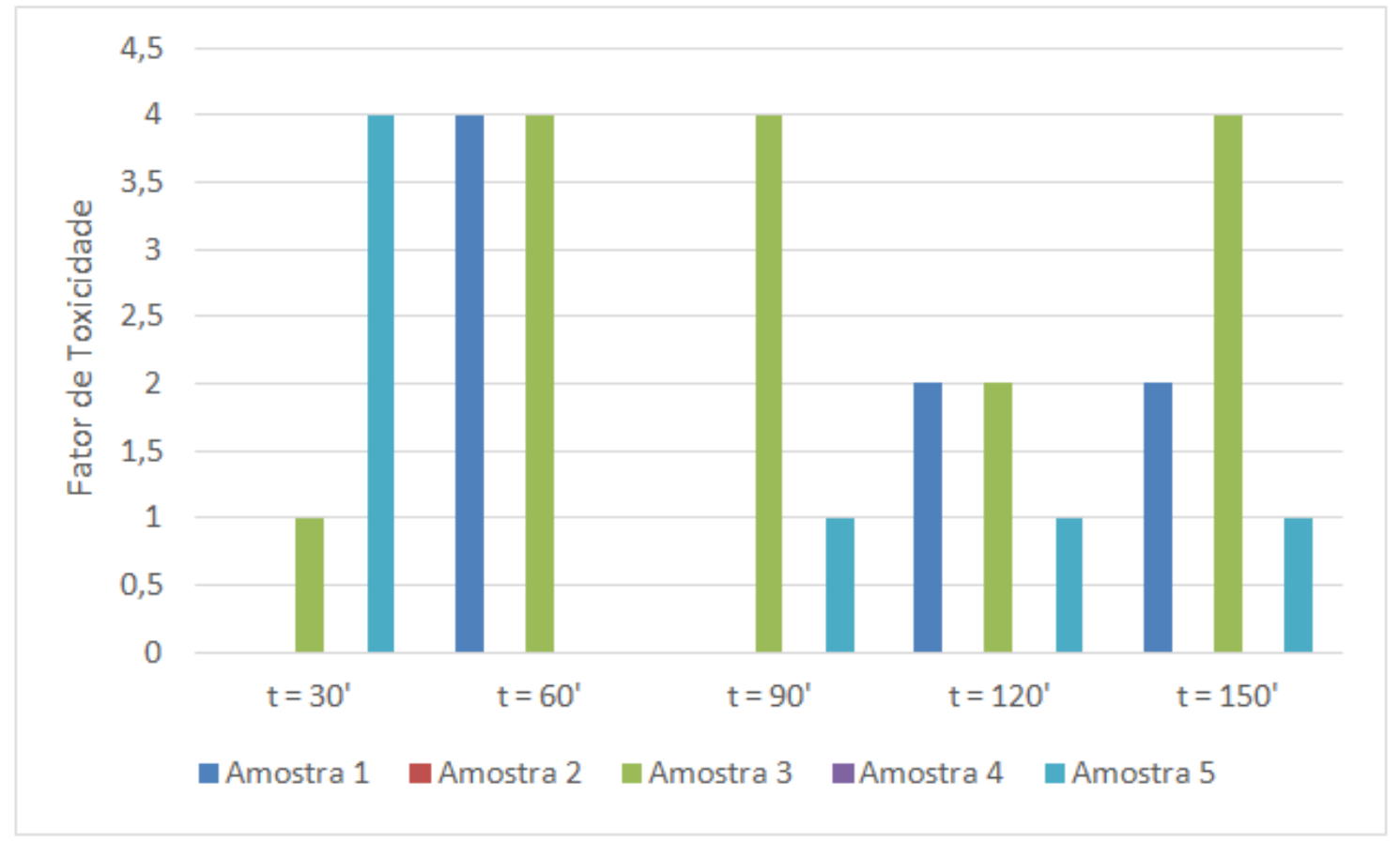

Figura 3. Fator de Toxicidade das alíquotas de lixiviação por percolação.

Na Figura 4 estão demostrados os percentuais de imobilidade dos organismos quando expostos à solução extratora e aos lixiviados, enquanto na Figura 5 estão expostos os valores de Fator de Toxicidade.

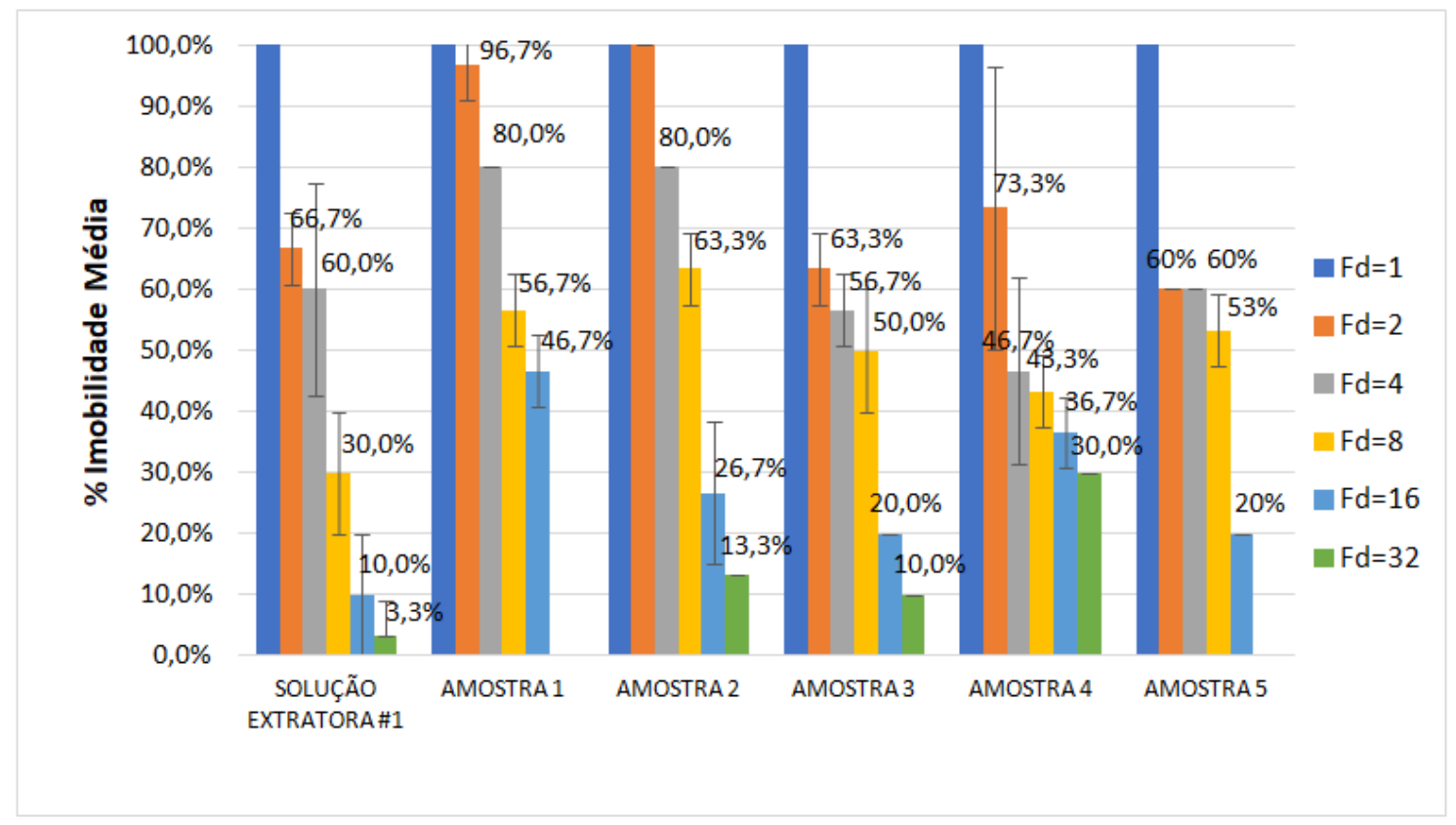

Figura 4. Imobilidade de Daphnia magna na exposição à solução e lixiviados de amostras segundo a ABNT NBR 10.005:2004, e respectivos fatores de diluição. 
Da análise da Figura 4 pode-se depreender que a imobilidade da Daphnia magna reduz com o aumento do fator de diluição para todas as amostras, o que é coerente. Vê-se que mesmo em fatores de diluição mais altos (16 e 32) é evidenciada ecotoxicidade (> 10\%) em todas as amostras ( 1 a 5). Pela observação dos resultados para a solução extratora \#1 na Figura 4, nota-se que seu impacto sobre a imobilidade é inferior quando comparado às cinco amostras de RAP, o que sugere que há ecotoxicidade incremental decorrente dos lixiviados das amostras.

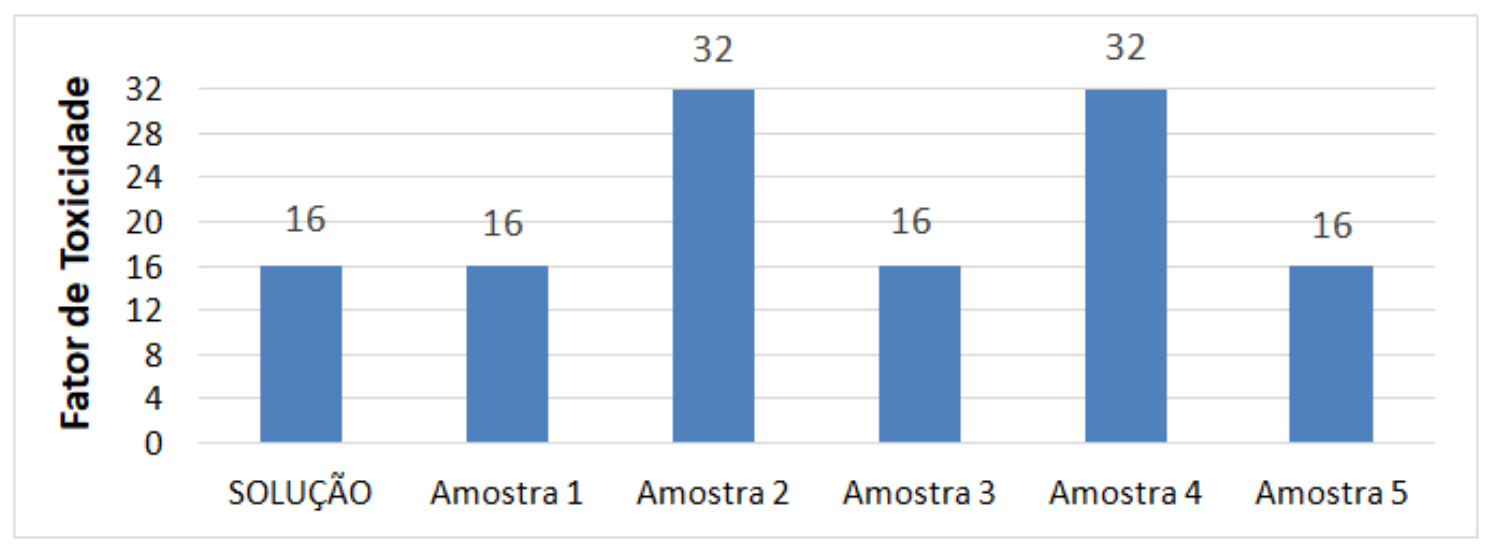

Figura 5. Fator de toxicidade das alíquotas de lixiviados de amostras obtidas segundo a ABNT NBR 10.005:2004.

No que concerne aos fatores de toxicidade, pela observação da Figura 5, conclui-se que todas as amostras analisadas (RAPs e solução extratora) são ecotóxicas à Daphnia magna, demandando fatores de diluição de 16 a 32. Não foi observada relação entre a ecotoxicidade medida e os teores de betume e massas unitárias das amostras. Atribui-se o fato à pequena variação de teor de betume $(<1 \%)$.

No que toca à eficiência de extração de poluentes das amostras, foi verificado que 0 método proposto pela ABNT NBR 10005:2004 (ABNT, 2004b) foi mais eficiente que o aparato experimental de percolação em coluna, pois os fatores de toxicidade observados para todas as amostras foram superiores. Atribui-se o fato à forma de agitação e dinâmica de contato entre a amostra e o lixiviante. Todavia, mesmo no método de recirculação em coluna foi possível observar toxicidade nos lixiviados de algumas das amostras (1, 3 e 5), o que corrobora os resultados.

Por outro lado, neste estudo foi possível identificar poluentes presentes no RAP a partir de ensaios com lixiviados obtidos em coluna, o que não foi possível nos estudos de Brantley e Townsend (1999).

Nestes termos, os resultados da presente pesquisa complementam os obtidos por Butera et al. (2014), Nagalli et al. (2015), Nagalli et al. (2016), Moares (2019) que observaram a presença de HPA's e metais em concentrações significativas em amostras de RAP's. Foi possível observar os efeitos ecotoxicológicos agudos em culturas de Daphnia magna. Tais efeitos, sinalizam aos técnicos da área que a disposição de resíduos asfálticos em solo deve atender a critérios técnicos, visando à minimização dos riscos ao meio ambiente. Mais estudos são necessários para verificar as taxas de desprendimento destes poluentes avaliados de forma que se possa compreender as formas mais adequadas de proteção ambiental aplicáveis. Não necessariamente deve-se pensar de imediato em 
sistemas de impermeabilização destes locais, mas o avanço de pesquisas no tema pode direcionar a escolha dos sistemas de proteção e de gestão ambiental aplicáveis.

\section{Conclusão}

Os estudos levados a efeito mostraram que os lixiviados de amostras de material fresado de pavimentos asfálticos apresentam potencial ecotóxico. A gestão ambiental de obras rodoviárias, com vistas à sustentabilidade ambiental do setor, deve estar atenta a este tema. Evidenciou-se que ambos os métodos de lixiviação utilizados foram eficientes na extração de poluentes das amostras, mas o método proposto pela ABNT NBR 10.005:2004 (ABNT, 2004b) revelou-se mais eficaz que o da extração por coluna.

Todas as amostras analisadas apresentaram fator de toxicidade para Daphnia magna significativo, variando de 16 a 32 vezes para as amostras analisadas segundo a ABNT NBR 10.005:2004 (ABNT, 2004b). Do estudo depreende-se que é necessário continuar investigando e quantificando os poluentes observados em amostras de material fresado, de modo que se tenham taxas seguras de desprendimento destes ou ainda que seja vislumbre seu enclausuramento, quando da realização de estoques ou aterros.

\section{Agradecimentos}

Os autores agradecem ao Conselho Nacional de Desenvolvimento Científico e Tecnológico e à Coordenação de Aperfeiçoamento de Pessoal de Nível Superior pelo suporte financeiro dado à pesquisa, por meio do Edital Universal Universal no 01/2016 e bolsas de estudo.

\section{Conflito de interesses}

Os autores declaram não haver conflito de interesses.

\section{Referências}

ABNT - Associação Brasileira de Normas Técnicas. ABNT NBR NM 27:2001 - Agregados Redução da amostra de campo para ensaios de laboratório. Rio de Janeiro: ABNT, 2001.

ABNT - Associação Brasileira de Normas Técnicas. ABNT NBR NM 248:2003 - Agregados - Determinação da composição granulométrica. Rio de Janeiro: ABNT, 2003.

ABNT - Associação Brasileira de Normas Técnicas. ABNT NBR 10.004:2004 - Resíduos sólidos - Classificação. Rio de Janeiro: ABNT, 2004a.

ABNT - Associação Brasileira de Normas Técnicas. ABNT NBR 10.005:2004 Procedimento para obtenção de extrato lixiviado de resíduos sólidos. Rio de Janeiro: ABNT, 2004b.

ABNT - Associação Brasileira de Normas Técnicas. ABNT NBR 10.007:2004 Amostragem de resíduos sólidos. Rio de Janeiro: ABNT, 2004c.

ABNT - Associação Brasileira de Normas Técnicas. ABNT NBR NM 45:2006 - Agregados Determinação da massa unitária e do volume de vazios. Rio de Janeiro: ABNT, 2006.

ABNT - Associação Brasileira de Normas Técnicas. ABNT NBR NM 26:2009 - Agregados Amostragem. Rio de Janeiro: ABNT, 2009. 
ABNT - Associação Brasileira de Normas Técnicas. ABNT NBR 16.208:2013 - Misturas asfálticas - Determinação do teor de betume pelo Soxhlet, pelo Rotarex e pelo refluxo duplo. Rio de Janeiro: ABNT, 2013.

ABNT - Associação Brasileira de Normas Técnicas. ABNT NBR 12.713:2016 Ecotoxicologia aquática - Toxicidade aguda - Método de ensaio com Daphnia spp (Crustacea, Cladocera). Rio de Janeiro: ABNT, 2016.

Bonfim, V. Fresagem de pavimentos asfálticos. 3. ed. São Paulo: Exceção, 2007.

Brantley, A. S.; Townsend, T. G. Leaching of pollutants from reclaimed asphalt pavement. $\begin{array}{lllll}\text { Environmental Engineering Science, } & \text { v. 16, } & \text { n. 2, } & \text { p. 105-116, }\end{array}$ https://doi.org/10.1089/ees.1999.16.105

Brasil. Resolução no 357, de 17 de março de 2005. Dispõe sobre a classificação dos corpos de água e diretrizes ambientais para o seu enquadramento, bem como estabelece as condições e padrões de lançamento de efluentes, e dá outras providências. Disponível em: <http://www2.mma.gov.br/port/conama/legiabre.cfm?codlegi=459>. Acesso em: 27 ago. 2018.

Butera, S.; Christensen, T. H.; Astrup, T. F. Composition and leaching of construction and demolition waste: Inorganic elements and organic compounds. Journal of Hazardous Materials, v. 276, p. 302-311, 2014. https://doi.org/10.1016/j.jhazmat.2014.05.033

CNT - Confederação Nacional dos Transportes. PIB do transporte em 2017 volta ao nível de 2010; investimentos caem. Disponível em: <http://www.cnt.org.br/ imprensa/noticia/pib-transporte-volta-niveis-2010-investimentos-caem>. Acesso em: 27 ago. 2018.

Dal Molin, D.; Costa, A. B.; Rieger, A.; Pra, D.; Lobo, E. A. Determinação das características de toxicidade ambiental do percolado de um aterro de resíduos industriais perigosos (estudo de caso). Tecno-Lógica, v. 14, n. 1, p. 5-10, 2010. https://doi.org/ 10.17058/tecnolog.v14i1.1197

Fonseca, P. Reciclagem de pavimentos rodoviários. Recipav, Cartaxo, 2002.

Legret, M. O. L. Demare, D. Jullien, A. Leaching of heavy metals and polycyclic aromatic hydrocarbons from reclaimed asphalt pavement. Water Research, v. 39, n. 15, p. 36753685, 2005. https://doi.org/10.1016/j.watres.2005.06.017

Moraes, D. Determinação de metais, HPA's e ecotoxicidade em amostras de lixiviados de resíduos de pavimentação asfáltica. Curitiba: UTFPR, 2019. (Dissertação de mestrado).

Nagalli, A.; Schneider, E. D.; Schroh, M.R. Investigação do potencial de contaminação ambiental associado à disposição em solo de resíduos asfálticos. ANAP Brasil, v. 9, n. 17, 2016. https://doi.org/10.17271/1984324091720161446

Nagalli, A.; Schneider, E. D.; Porfirio, M. A. S.; Schroh, M. R.; Schamne, A. N.; Martins, L. R. R.; Mymrine, V. Potential of environmental contamination associated with disposal of asphalt waste in soil. The Electronic Journal of Geotechnical Engineering, v. 20, p. 6041-6051, 2015.

Sadecki, R. W.; Busacker, G. P.; Moxness, K. L.; Faruq, K. C.; Allen, L. G. An investigation of water quality in runoff from stockpiles of salvaged concrete and bituminous paving. St. Paul: Minnesota Department of Transportation, 1996.

Yusuf, M.; Ali, A.; Beizhan, Y.; Anne, E.; Huiming, Y. Environmental impacts of reclaimed asphalt pavement (RAP). New Jersey: New Jersey Departament of Transportation, 2017. 
Zhang, J.; Wang, J.; Hua, P.; Krebs, P. The qualitative and quantitative source apportionments of polycyclic aromatic hydrocarbons in size dependent road deposited sediment. Science of the Total Environment, v. 505, p. 90-101, 2015. https://doi.org/10.1016/j.scitotenv.2014.09.091

\footnotetext{
(CC) Informação da Licença: Este é um artigo Open Access distribuído sob os termos da Licença Creative Commons Attribution, que permite uso irrestrito, distribuição e reprodução em qualquer meio, desde que a obra original seja devidamente citada.
} 